\title{
Mipartoxin-I, a novel three-finger toxin, is the major neurotoxic component in the venom of the redtail coral snake Micrurus mipartitus (Elapidae)
}

\author{
Paola Rey-Suárez ${ }^{\mathrm{a}}$, Rafael Stuani Floriano ${ }^{\mathrm{b}}$, Sandro Rostelato-Ferreira ${ }^{\mathrm{b}}$, \\ Mónica Saldarriaga-Córdoba ${ }^{c}$, Vitelbina Núñez ${ }^{\mathrm{a}, \mathrm{d}}$, Léa Rodrigues-Simioni ${ }^{\mathrm{b}}$, Bruno Lomonte ${ }^{\mathrm{e}, *}$ \\ a Programa de Ofidismo y Escorpionismo, Universidad de Antioquia, Medellín, Colombia \\ ${ }^{\mathrm{b}}$ Departamento de Farmacologia, Faculdade de Ciências Médicas, Universidade Estadual de Campinas, SP, Brazil \\ ${ }^{\mathrm{c}}$ Facultad de Ciencias, Universidad Iberoamericana de Ciencias y Tecnología, Chile \\ ${ }^{\mathrm{d}}$ Escuela de Microbiología, Universidad de Antioquia, Medellín, Colombia \\ e Instituto Clodomiro Picado, Facultad de Microbiología, Universidad de Costa Rica, San José, Costa Rica
}

\section{A R T I C L E I N F O}

\section{Article history:}

Received 1 March 2012

Received in revised form 4 May 2012

Accepted 24 May 2012

Available online 4 June 2012

\section{Keywords:}

Mipartoxin-I

Three-finger toxin

Micrurus mipartitus

Snake venom

Neurotoxicity

\begin{abstract}
A B S T R A C T
The major venom component of Micrurus mipartitus, a coral snake distributed from Nicaragua to northern South America, was characterized biochemically and functionally. This protein, named mipartoxin-I, is a novel member of the three-finger toxin superfamily, presenting the characteristic cysteine signature and amino acid sequence length of the short-chain, type-I, $\alpha$-neurotoxins. Nevertheless, it varies considerably from related toxins, with a sequence identity not higher than $70 \%$ in a multiple alignment of 67 proteins within this family. Its observed molecular mass (7030.0) matches the value predicted by its amino acid sequence, indicating lack of post-translational modifications. Mipartoxin-I showed a potent lethal effect in mice (intraperitoneal median lethal dose: $0.06 \mu \mathrm{g} / \mathrm{g}$ body weight), and caused a clear neuromuscular blockade on both avian and mouse nerve-muscle preparations, presenting a post-synaptic action through the cholinergic nicotinic receptor. Since mipartoxin-I is the most abundant (28\%) protein in M. mipartitus venom, it should play a major role in its toxicity, and therefore represents an important target for developing a therapeutic antivenom, which is very scarce or even unavailable in the regions where this snake inhabits. The structural information here provided might help in the preparation of a synthetic or recombinant immunogen to overcome the limited venom availability.
\end{abstract}

(c) 2012 Elsevier Ltd. All rights reserved.

\section{Introduction}

Snake venoms are recognized as a vast, yet largely unexplored source of bioactive proteins with potent toxic effects. Acquisition of such toxic proteins was accomplished through the recruitment of a small number of 'non-toxic' genes for expression in specialized oral glands, followed by an accelerated evolution process of divergence

\footnotetext{
* Corresponding author. University of Costa Rica, Instituto Clodomiro Picado, San Jose, Costa Rica. Tel.: +506 2229 0344; fax: +505 22920485. E-mail address: bruno.lomonte@ucr.ac.cr (B. Lomonte).
}

and neofunctionalization under strong positive selection (Nakashima et al., 1993; Fry et al., 2006). This evolutionary pathway allowed the advanced snakes (Caenophidia) to undergo a striking change in their mode of subduing prey, shifting from a mechanical (based on constriction) to a biochemical (based on venom injection) strategy (Calvete et al., 2009).

Highly venomous snakes of medical relevance are classified within the families Atractaspidae, Viperidae, and Elapidae (Fry et al., 2003a,b). The latter contains over 60 genera and nearly 300 species, one-third of which belong to 'coral snakes', a major radiation encompassing six genera 
distributed in Asia and the Americas. The New World coral snakes are currently classified within the genera Micrurus, Micruroides, and Leptomicrurus, the former being the most diverse, including over 70 species (Castoe et al., 2007). Is spite of the extraordinary biological diversity and complexity of coral snakes, distribued from Southern USA to Argentina, factors such as low venom yields, and their poor survival in captivity, pose important limitations for the study of their venoms, as well as for the production of therapeutic antivenoms. Nevertheless, newer sensitive techniques for protein analysis have opened possibilities to characterize such scarce biological materials, and accordingly, a few proteomes of Micrurus venoms have been described recently (Olamendi-Portugal et al., 2008; Fernández et al., 2011; Corrêa-Netto et al., 2011; Rey-Suárez et al., 2011; Ciscotto et al., 2011).

Micrurus mipartitus, commonly known as 'redtail coral snake', 'rabo de ajî', or 'gargantilla', inhabits the Caribbean versants of Nicaragua, Costa Rica, the central Panamá isthmus, and large areas of Ecuador, Colombia, and Venezuela. Although this snake causes few human envenomings in comparison to pitvipers (family Viperidae), accidents may be fatal if unattended. Patients present peripheral neurotoxic manifestations such as bilateral ptosis and progressive respiratory paralysis which may require ventilatory support (Otero, 1994). A major medical difficulty in dealing with envenomings by $M$. mipartitus is the scarcity, or even complete unavailability in most of its geographic range, of a specific therapeutic antivenom. This problem is aggravated by the lack of cross-protection by more readily available antivenoms prepared against species such as the Central American coral snake Micrurus nigrocinctus, due to their antigenic differences (Cohen et al., 1971; Bolaños et al., 1975, 1978; Rey-Suárez et al., 2011).

Proteomic analyses of the venoms of $M$. mipartitus from Colombia and Costa Rica were recently reported (Rey-Suárez et al., 2011), aiming to provide a basic platform that could be useful in the design of an antivenom. The study identified a prominent venom component belonging to the three-finger toxin (3FTx) family which caused lethality in mice. In the present work, this protein was isolated and characterized biochemically and functionally as a potent short-chain neurotoxin. The protein, named mipartoxin-I, is a new member of the 3FTx superfamily which shows considerable amino acid sequence differences with other short-chain neurotoxins described in the venoms of Elapidae snakes, including other Micrurus species. Due to its abundance in the venom of M. mipartitus, and its high toxicity, the primary structure and threedimensional modeling of mipartoxin-I here reported might be useful for the preparation of an immunogen, recombinant or synthetic, to elicit neutralizing antibodies for the treatment of envenomings by this snake species.

\section{Materials and methods}

\subsection{Venom and toxin isolation}

Venom was collected from five adult specimens of M. mipartitus from Antioquia, Colombia. The venom was pooled, lyophilized, and stored at $-20^{\circ} \mathrm{C}$. Fractionation of venom ( $2 \mathrm{mg}$ in $200 \mu \mathrm{L}$ of water containing $0.1 \%$ trifluoroacetic acid; TFA) was performed by RP-HPLC on a C18 column $(4.6 \times 250 \mathrm{~mm}, 5 \mu \mathrm{m}$ particle; Teknokroma) using an Agilent 1200 chromatograph. Elution was performed at $1 \mathrm{ml} / \mathrm{min}$ by applying a gradient toward acetonitrile containing $0.1 \%$ TFA (solution B), as follows: $5 \%$ B for $5 \mathrm{~min}$, $5-15 \%$ B over $10 \mathrm{~min}, 15-45 \%$ B over $60 \mathrm{~min}$, and 45-70\% B over $12 \mathrm{~min}$, as previously described (Rey-Suárez et al., 2011). Absorbance was monitored at $215 \mathrm{~nm}$, and the major peak eluting at $\sim 26.5 \mathrm{~min}$, named mipartoxin-I, was manually collected, dried in a vacuum centrifuge (Savant), and stored at $-20^{\circ} \mathrm{C}$.

\subsection{MALDI-TOF mass spectrometry (MS)}

Mipartoxin-I was diluted in water containing 0.1\% TFA, and dilutions ranging from 1000 to 10 ng were mixed at $1: 1$ with either saturated sinapinic acid or $\alpha$-cyano-hydroxycinnamic acid in 50\% acetonitrile, 0.1\% TFA, and spotted $(1 \mu \mathrm{L})$ onto an OptiToF-384 plate for MALDI-TOF MS analysis. Spectra were acquired on an Applied Biosystems 4800-Plus instrument, in linear positive mode, using 500 shots/spectrum and a laser intensity of 4200 , over the $\mathrm{m} / \mathrm{z}$ range 4000-40,000. External calibration was performed with CalMix-5 standards (ABSciex) spotted on the same plate.

\subsection{Electrospray ionization (ESI) MS}

Mipartoxin-I, dissolved in $10 \mu \mathrm{L}$ of $0.1 \%$ formic acid, was loaded in a capillary tip (Proxeon) for direct infusion in a nano-ESI source coupled to an Applied Biosystems Q-Trap 3200 mass spectrometer. Ionization was performed at $1200 \mathrm{~V}$ and spectra were acquired in positive Enhanced Multi-Charge mode, in the $m / z$ range 400-1600. Chargestate and deconvolution of the ion series were analyzed with the aid of the Bayesian protein reconstruction tool of BioAnalyst v.1.5 software (ABSciex), and confirmed by manual calculation.

\subsection{Amino acid sequencing}

Mipartoxin-I $(250 \mu \mathrm{g})$ was dissolved in $50 \mathrm{mM}$ ammonium bicarbonate and subjected to reduction with dithiothreitol $(10 \mathrm{mM})$ and alkylation with iodoacetamide $(50 \mathrm{mM})$. An aliquot of the reduced-alkylated protein was subjected to N-terminal sequencing on a Shimadzu PPSQ33A Protein Sequencer, according to the manufacturer. The rest of this material was digested overnight with sequencing grade bovine trypsin (in $25 \mathrm{mM}$ ammonium bicarbonate, $10 \%$ acetonitrile) at $37{ }^{\circ} \mathrm{C}$. The resulting tryptic peptides were separated by RP-HPLC on a C4 column $(4.6 \times 150 \mathrm{~mm}$; Vydac), eluted at $1 \mathrm{ml} / \mathrm{min}$ with a $0-70 \%$ acetonitrile gradient over $40 \mathrm{~min}$, and manually collected. Each peak was subjected to MS/MS fragmentation and de novo amino acid sequencing, using the above-mentioned mass spectrometers. For MALDI-TOF-TOF analyses, fragmentation spectra were acquired at $2 \mathrm{kV}$ in positive reflectron mode, using $\alpha$-cyano-hydroxycinnamic acid as matrix, 500 shots/ spectrum, and a laser intensity of 3000 . Spectra were searched using the Paragon ${ }^{\circledR}$ algorithm of ProteinPilot 4.0 
(ABSciex) and the UniProt/SwissProt database (20100622), or interpreted manually. Peptides that did not produce well-resolved fragmentation spectra using MALDI were further subjected to nESI-MS/MS. Selected doubly- or triplycharged peptide ions were analyzed in Enhanced Resolution mode (250 amu/s), and fragmented using the Enhanced Product Ion tool, with Q0 trapping. Settings were: Q1, unit resolution; collision energy, 25-45 eV; linear ion trap Q3 fill time, $250 \mathrm{~ms}$; and Q3 scan rate, $1000 \mathrm{amu} / \mathrm{s}$. The resulting spectra were manually interpreted with the aid of the BioAnalyst 1.5 Manual Sequencing tool.

\subsection{Homology modeling}

The Swiss-Model automated protein structure homology-modeling server (http://swissmodel.expasy.org/; Kiefer et al., 2009) was used to model the three-dimensional structure of mipartoxin-I. Proteins with highest sequence identity to this toxin were searched with this server and tested as templates. The resulting models were superimposed and examined using Swiss-PDB Viewer v.4.0 (http://www.expasy.org/spdbv/; Guex and Peitsch, 1997) or DS Viewer Pro v.6.0 (Accelrys). The best model was obtained when using as template the crystal structure coordinates of CTXA5, a non-cytolytic cardiotoxin variant from the venom of the cobra Naja atra (PDB code $1 \mathrm{KXI}$ ), having $38 \%$ amino acid sequence identity. The resulting model of mipartoxin-I was evaluated with ProCheck (Laskowski et al., 1993).

\subsection{Phylogenetic relationships}

Phylogenetic relationships of mipartoxin-I to other members of the 3FTx superfamily were analyzed using 67 related amino acid sequences from venom proteins isolated from the genera Micrurus, Pseudonaja, Ophiophagus, Oxyuranus, Bungarus, Naja, Dendroaspis, Haemachatus, and Aspidelaps, selected by a standard protein BLAST search (Altschul et al., 1990). A hypothetical uncharacterized protein from the lizard Anolis carolinensis (code XP_003217978) was utilized as outgroup. Amino acid sequences were retrieved from GenBank (access codes indicated in Fig. 5) and aligned using BioEdit v.7.0 (Hall, 1999). The final number of amino acid positions was 79, after including gaps to maximize alignments, and the aligned sequences were ordered by descending percent identity values in comparison to mipartoxin-I. Phylogenetic inference was calculated by the Bayesan inference algorithm, performed with MrBayes v.3.1.2 (Ronquist and Huelsenbeck, 2003). A search for the amino acid substitution model that better described the evolutive process of the multiple sequence alignment of the 3FTxs was performed with the ProtTest software (Abascal et al., 2005), using the Akaike selection criterium.

\subsection{Animals}

Male Swiss mice (25-30 g) were obtained from the Multidisciplinary Center for Biological Investigation (CEMIB/UNICAMP), and male HY-LINE W36 chicks (4-8 days old) were supplied by Granja Globo Aves Agrovícola (Mogi Mirim, SP, Brazil). These animals were housed at $25 \pm 3{ }^{\circ} \mathrm{C}$ on a $12 \mathrm{~h}$ light/dark cycle with free access to food and water, and were used for the ex vivo neurotoxicity studies at the University of Campinas. CD-1 mice (16-18 g) of either sex were used for lethality assays at the University of Costa Rica. All experiments were performed following protocols approved by the corresponding institutional committees for the ethical use of research animals.

\subsection{Mouse lethality assay}

Variable doses of mipartoxin-I, dissolved in $250 \mu \mathrm{L}$ of $0.04 \mathrm{M}$ sodium phosphate, $0.12 \mathrm{M} \mathrm{NaCl}$ buffer (PBS; $\mathrm{pH} 7.2$ ), were injected by the intraperitoneal route in CD-1 mice (16-18 g). Deaths were scored after $48 \mathrm{~h}$, and the median lethal dose $\left(\mathrm{LD}_{50}\right)$ was calculated by probits (Trevors, 1986$)$.

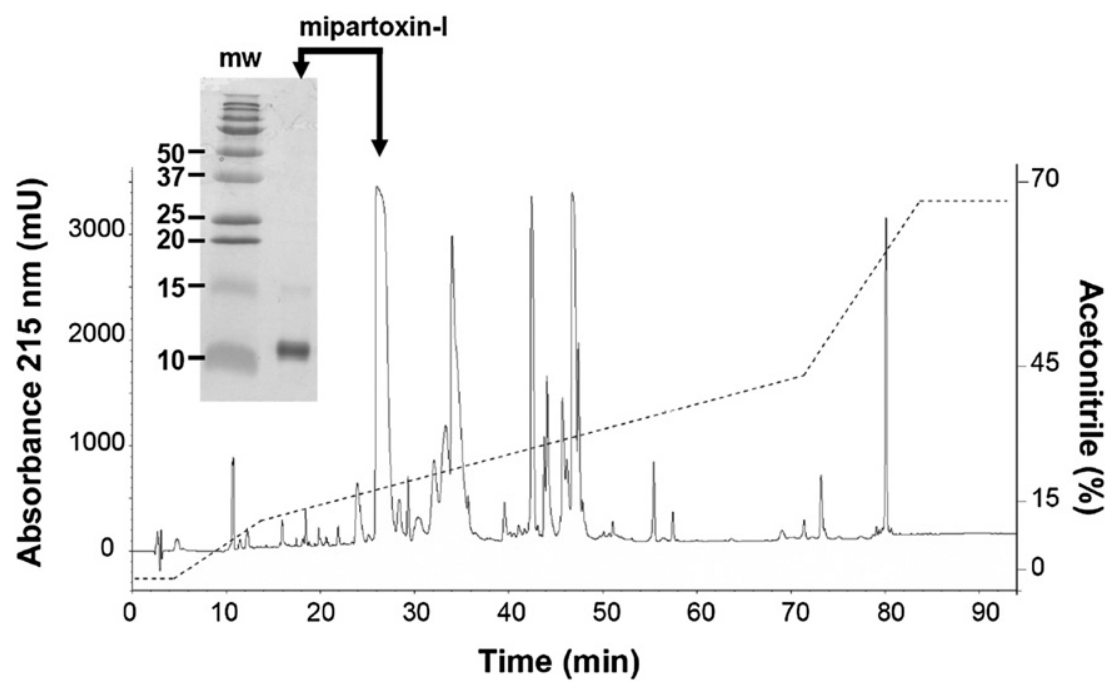

Fig. 1. Isolation of mipartoxin-I from the crude venom of Micrurus mipartitus. Venom ( $2 \mathrm{mg})$ was fractionated by RP-HPLC on a C18 column $(4.6 \times 250 \mathrm{~mm}, 5 \mu \mathrm{m}$ particle size), using a water/acetonitrile gradient as described in Materials and Methods. The arrow indicates the peak corresponding to mipartoxin-I, eluting at $\sim 16.5 \mathrm{~min}$, and analyzed by SDS-PAGE (15\% gel) under reducing conditions (insert). Molecular weight markers (mw) are indicated at the left, in kDa. 

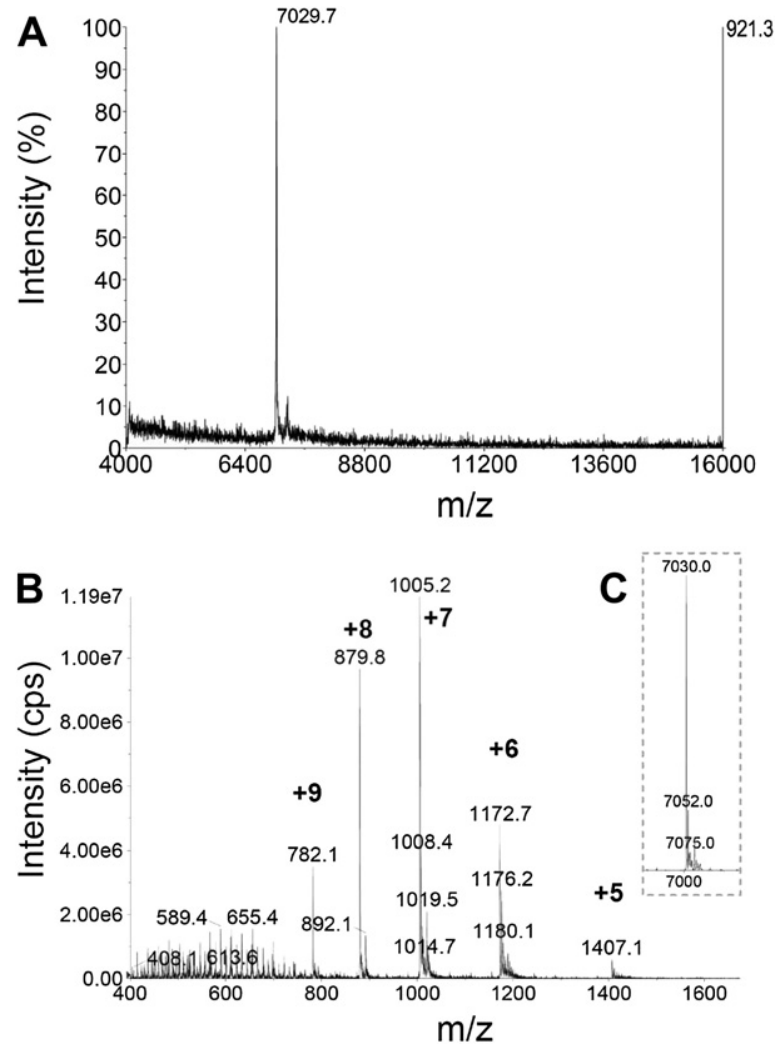

Fig. 2. Molecular mass analyses of mipartoxin-I by (A) MALDI-TOF in positive linear mode, and (B) direct infusion nESI-MS in positive enhanced multi-charge mode, as described in Materials and Methods. The inset (C) shows the deconvolution of the multi-charged ion series shown in (B).

\subsection{Mouse phrenic-nerve diaphragm}

Phrenic nerve-diaphragm preparations (Bülbring, 1946) were obtained from mice anesthetized with isoflurane (Cristália, Brazil) and euthanized by exsanguination. The diaphragm was removed and mounted under a tension of $5 \mathrm{~g}$ in a $5 \mathrm{ml}$ organ bath containing Tyrode solution ( $\mathrm{pH} 7.4$, $37^{\circ} \mathrm{C}$ ) of the following composition ( $\mathrm{mM}$ ): $\mathrm{NaCl} 137, \mathrm{KCl} 2.7$, $\mathrm{CaCl}_{2}$ 1.8, $\mathrm{MgCl}_{2}$ 0.49, $\mathrm{NaH}_{2} \mathrm{PO}_{4}$ 0.42, $\mathrm{NaHCO}_{3}$ 11.9, and glucose 11.1 , aerated with $95 \% \mathrm{O}_{2}$ and $5 \% \mathrm{CO}_{2}$. Supramaximal stimuli ( $4 \times$ threshold, $0.1 \mathrm{~Hz}, 0.2 \mathrm{~ms}$ for indirect stimulation and $70 \mathrm{~Hz}, 0.2 \mathrm{~ms}$ for tetanic stimulation) delivered from a Grass S48 stimulator were applied to the nerve through bipolar electrodes. Isometric muscle twitchtension was recorded by a force-displacement transducer (Load Cell BG-10 GM) coupled to a Gould model RS3400 physiograph via a Gould universal amplifier. The preparations were allowed to stabilize for at least $20 \mathrm{~min}$ before the addition of mipartoxin-I ( 0.1 or $0.5 \mu \mathrm{g} / \mathrm{ml})$.

\subsection{Chick biventer cervicis preparation}

Biventer cervicis muscles obtained from male chicks (Ginsborg and Warriner, 1960) sacrificed with isoflurane were mounted under a tension of $1 \mathrm{~g} / 0.5 \mathrm{~cm}$ in a $5 \mathrm{ml}$ organ bath containing warmed $\left(37{ }^{\circ} \mathrm{C}\right)$, aerated $\left(95 \% \mathrm{O}_{2}, 5 \% \mathrm{CO}_{2}\right)$ Krebs solution of the following composition (mM): $\mathrm{NaCl}$ 118.7, $\mathrm{KCl}$ 4.7, $\mathrm{CaCl}_{2}$ 1.8, $\mathrm{NaHCO}_{3} 25, \mathrm{MgSO}_{4}$ 1.17, $\mathrm{KH}_{2} \mathrm{PO}_{4} 1.17$, and glucose 11.65 , pH 7.5. A bipolar platinum ring electrode was placed around the tendon within which runs the nerve trunk supplying the muscle. Field stimulation $(0.1 \mathrm{~Hz}, 0.2 \mathrm{~ms}, 4-6 \mathrm{~V})$ was done with a Grass S48 stimulator (Astro-Med Inc.). Muscle contractions and contractures were recorded isometrically via a force-displacement transducer (Load Cell BG-10 GM, Kulite Semiconductor Products) coupled to a Gould model RS3400 physiograph via a Gould universal amplifier (Gould Inc.). Contractures to exogenously applied acetylcholine ( $\mathrm{ACh}, 110 \mu \mathrm{M})$ and $\mathrm{KCl}(40 \mathrm{mM})$ were obtained in the absence of field stimulation prior to the addition of mipartoxin-I and at the end of the experiment, as a test for the presence of myotoxic and neurotoxic activities (Harvey et al., 1994). The preparations were allowed to stabilize for at least $20 \mathrm{~min}$ before the addition of $\mathrm{ACh}, \mathrm{KCl}$ or mipartoxin-I $(0.1$ or $0.5 \mu \mathrm{g} / \mathrm{ml})$ to the bath. Twitch-tension responses to mipartoxin-I were monitored for up to $60 \mathrm{~min}$, depending on the toxin concentration. In some preparations pretreated with mipartoxin-I $(0.5 \mu \mathrm{g} / \mathrm{ml})$, neostigmine $(6 \mu \mathrm{M})$ was added after $80 \%$ twitch-tension blockade to examine whether the neurotransmission can be recovered.

\subsection{Membrane resting potential}

The effect of mipartoxin-I on the membrane resting potential and miniature end-plate potentials (MEPPs) was recorded using mouse hemidiaphragm muscle mounted in a lucite chamber containing Tyrode solution ( $\mathrm{pH}$ 7.0), as previously described (Oshima-Franco et al.,

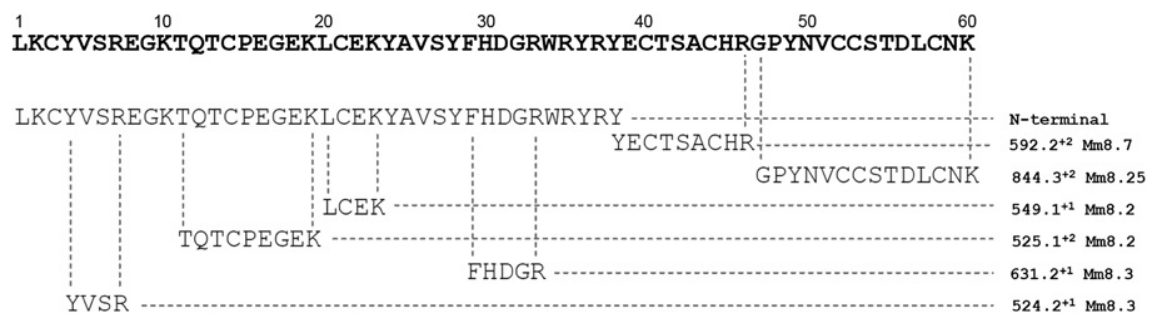

Fig. 3. Primary structure determination of mipartoxin-I. The complete sequence was obtained by N-terminal Edman degradation (amino acid residues 1-38) combined with de novo sequencing of tryptic fragments of the toxin by MALDI-TOF-TOF or nESI-MS-MS, as described in Materials and Methods. The column at the right shows the $m / z$ values and charge state of tryptic fragments that were sequenced de novo. The amino acid sequence predicts a molecular mass that matches the experimental values observed by both MALDI-TOF and nESI-MS analyses, shown in Fig. 2. 
A

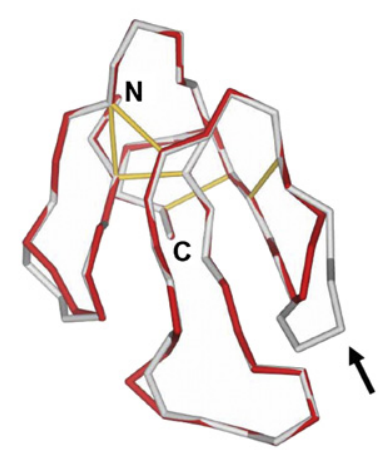

B

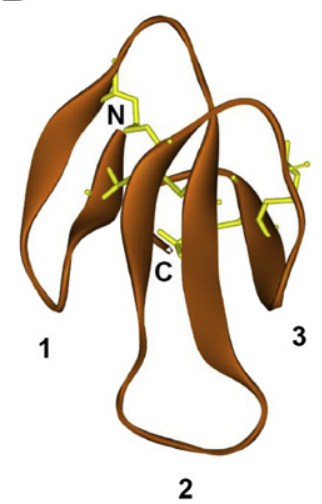

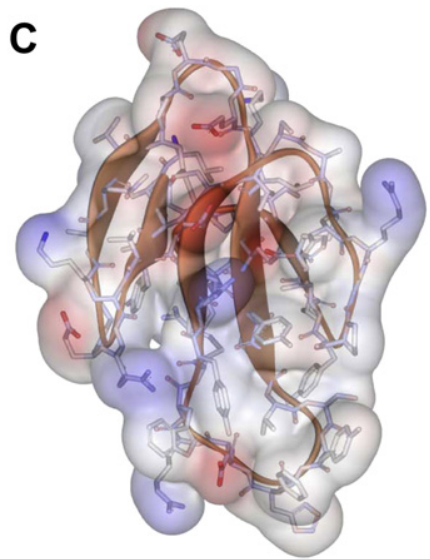

mipartoxin-I LKCYVSRE-GKTQTCPEGEKLCEKYAVSYFHDGRWRYRYECTSACHRG---PYNVCCSTDLCNK Naja CTXA5 LKCHNTQLPFIYKTCPEGKNLCEKATLKKFP-LKEPVKRGCADNCPKNSALLKYVCCSTDKCN-

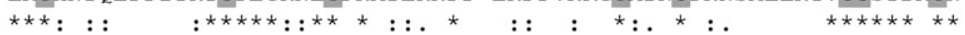

Fig. 4. Homology modeling of the three-dimensional structure of mipartoxin-I. Cardiotoxin CTXA5, a 3FTx from the cobra Naja atra (PDB code 1KXI), having 38\% amino acid sequence identity (aligned at the bottom), was used as template in the Swiss-Model homology-modeling server, as described in Materials and Methods. (A) Backbone superposition of Naja cardiotoxin CTXA5 (gray) and mipartoxin-I (red). The arrow points at the major structural difference, located in the third loop of the "three-finger" structure. (B) Structural model of mipartoxin-I, in ribbons representation, showing the N- and C-terminus, and the characteristic loops (1,2, and 3) of the three-finger toxins. Disulfide bonds are represented as yellow sticks. (C) surface electrostatic potential representation of the structural model shown in (B). Blue: positive; red: negative. Images were drawn with the DS Viewer software v.6.0. (For interpretation of the references to color in this figure legend, the reader is referred to the web version of this article.)

2004). In experiments conducted to record both, RP and MEPPs (displayed on a Tektronix oscilloscope) measurements were obtained at various intervals from control $\left(t_{0}\right)$ and toxin-treated preparations $\left(t_{15}, t_{30}, t_{45}\right.$ and $\left.t_{60}\right)$. MEPPs amplitude was grouped in $0.4 \mathrm{mV}$ intervals. Some preparations were incubated with toxin for $60 \mathrm{~min}$, and exogenous carbachol (Cch, $12.5 \mu \mathrm{g} / \mathrm{ml}$ ) was added to the organ bath to test its ability to induce membrane depolarization.

\subsection{In vitro cytotoxicity}

Mipartoxin-I was added to subconfluent cultures of C2C12 myogenic cells (ATCC CRL-1772) to test for cytolytic activity. After $3 \mathrm{~h}$ of incubation at $37^{\circ} \mathrm{C}$, the lactate dehydrogenase activity of supernatants $(40 \mu \mathrm{L})$ was determined using a kinetic UV assay (LDH, Biocon). Culture medium alone (Dulbecco's modification of Eagle's medium with 10\% fetal calf serum), or medium containing $0.1 \%$ Triton X-100, were used as reference points for 0 and $100 \%$ cytotoxicity, respectively (Lomonte et al., 1999). The crude venom of the cobra Naja nigricollis, which contains abundant 3FTxs cytotoxins (Méndez et al., 2011), was used as a positive control.

\subsection{Statistical analyses}

Each experimental protocol for neurotoxic assays was repeated four times and the results were reported as the mean \pm SEM. Repeated-measures analysis of variance (ANOVA) was used for statistical comparison of the data, with a value of $p<0.05$ indicating significance. All data analyses were performed using the OriginPro v.8.0 software.

\section{Results}

\subsection{Isolation of mipartoxin-I}

Using the RP-HPLC gradient previously developed for the proteomic characterization of the venom of M. mipartitus from Colombia (Rey-Suárez et al., 2011), the prominent peak eluting at $\sim 26.5$ min (Fig. 1), here named mipartoxin-I, was purified. Integration of the signal peak area at $215 \mathrm{~nm}$ indicates that this toxin represents $28 \%$ of the total venom proteins. SDS-PAGE of mipartoxin-I under reducing conditions showed a single band migrating at $\sim 10 \mathrm{kDa}$ (Fig. 1 insert), a slightly higher value than expected on the basis of MS analyses (see below). A tryptic peptide $\left(m / z 463.2^{+2}\right)$ obtained after in-gel digestion of the protein band initially identified it as a member of the 3FTx superfamily, by presenting the de novo sequence $\mathrm{L}(\mathrm{I}) \mathrm{K}(\mathrm{Q})$ CYVSR by nESI-MS-MS. This protein was isolated by running the RP-HPLC procedure four times ( $2 \mathrm{mg}$ of crude venom per run), with reproducible results.

\subsection{Mass spectrometry and amino acid sequence}

Homogeneity and molecular mass of mipartoxin-I were evaluated by MALDI-TOF (Fig. 2A) and nESI-MS (Fig. 2B) analyses. The first confirmed the high purity of the isolated protein, in particular showing no contamination with components in the molecular mass range of phospholipases $A_{2}(\sim 13,000-14,000$; Fig. $2 A)$, which are also abundant components of this venom. By nESI-MS (Fig. 2B), the molecular mass of mipartoxin-I was calculated at $7030.0 \pm 0.5$ by deconvolution of its observed multi-charged state $m / z$ values (Fig. 2C). The mass values observed by MALDI-TOF and nESI-MS are in close agreement. 


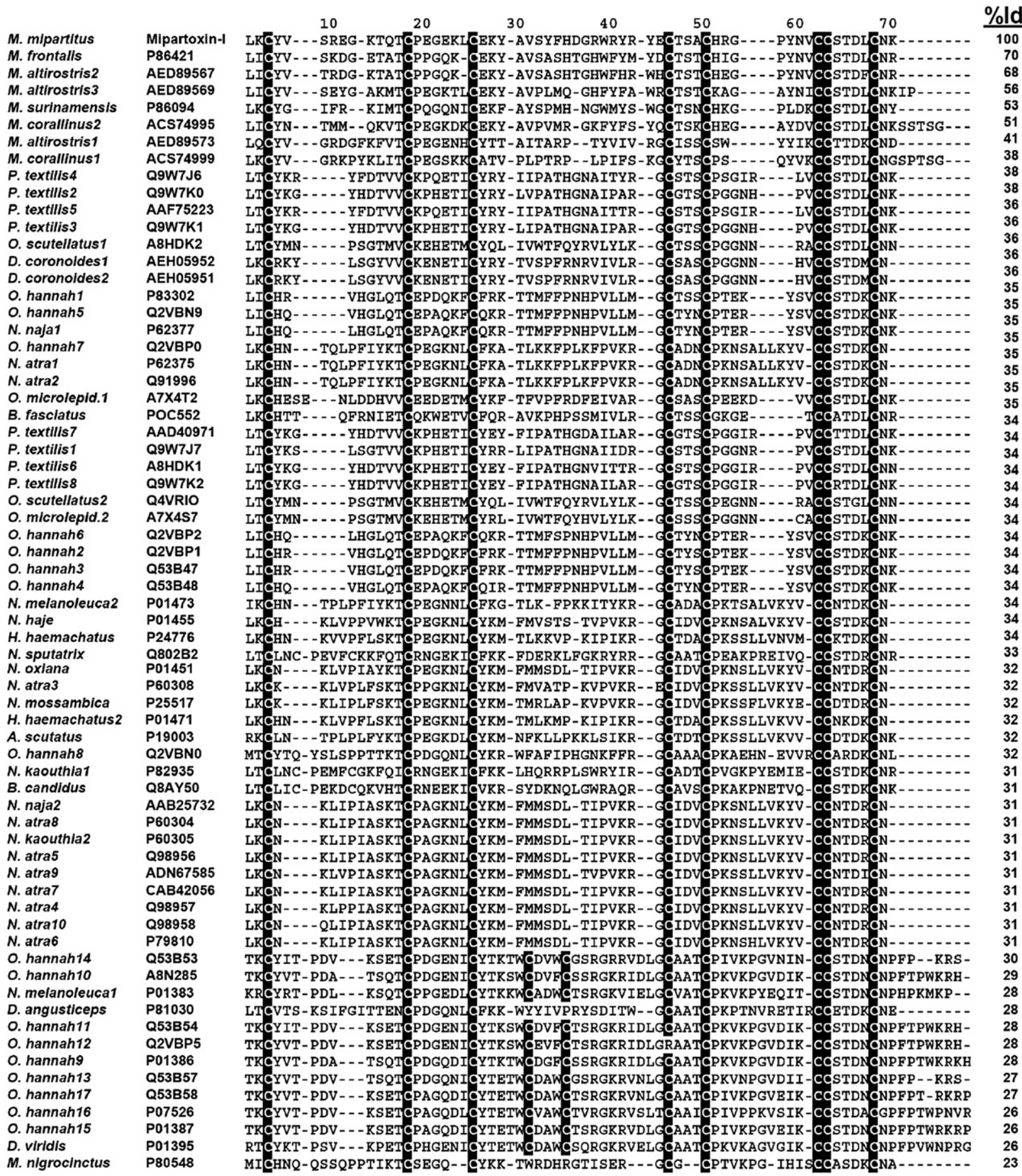

Fig. 5. Multiple sequence alignment of mipartoxin-I with three-finger toxins from elapid snake venoms. Protein access codes are indicated next to the snake species name. The last column indicates the percent identity values (\%Id) in comparison to mipartoxin-I. Cysteine residues are highlighted with a black background.

The complete amino acid sequence of mipartoxin-I was determined, as shown in Fig. 3. The N-terminal 38 amino acids were obtained by direct Edman sequencing of the protein. De novo sequencing by MS/MS of HPLC-separated tryptic fragments of the reduced and alkylated protein provided four internal peptides $\left(549.1^{+1}, 525.1^{+2}, 631.2^{+1}\right.$ and $524.2^{+1}$ ) that matched segments of the $\mathrm{N}$-terminal sequence, as well as two additional peptides that completed 
the sequence $\left(592.2^{+2}\right.$ and $844.3^{+2}$ ). The predicted theoretical mass of the sixty-amino acid sequence is 7037.98 (average mass), which is in agreement with the observed mass of $7030.0 \pm 0.5$, considering the presence of eight cysteines engaged in four disulfide bonds (loss of $8 \mathrm{H}^{+}$), characteristic of the short-chain 3FTx superfamily. Further, the obtained sequence predicts mipartoxin-I to be a basic protein, with a calculated pI of 8.5 , according to the Compute $\mathrm{Mw} / \mathrm{pI}$ tool at http://web.expasy.org/compute_pI/. The amino acid sequence of mipartoxin-I was submitted to the SwissProt/UniProt database, and assigned the access code B3EWF8.

\subsection{Homology modeling}

3FTxs for which three-dimensional structures are available at the RCSB Protein Data Bank showed highest sequence identity values with mipartoxin-I within the range of $27-39 \%$. After testing these different 3FTxs as templates in the Swiss-Model server, the homology model obtained using as template a non-cytolytic cardiotoxin isoform from $N$. atra $(1 \mathrm{KXI}$; $38 \%$ amino acid sequence identity), provided the best results, whereas the use of other 3FTxs as templates provided poor models (data not shown). Evaluation of the best model (vs. 1KXI) with ProCheck indicated $98 \%$ of residues in allowed regions $(74.5 \%$ in most favored regions, $19.6 \%$ in additional allowed regions, and $3.9 \%$ in generously allowed regions). The predicted mipartoxin-I model superimposed over the backbone residues of the Naja 3FTx is shown in Fig. 4A. Their structural comparison results in a r.m.s. value of $1.51 \AA$ for $\alpha$-carbon atoms and $1.59 \AA$ for backbone. The predicted core region of mipartoxin-I is virtually identical to the template, showing full spatial conservation of the disulfide bonds. Slight spatial differences are predicted at the tips of loops 1 and 2, whereas loop 3 presents a significant deviation (Fig. 4A) which is consistent with the presence of two additional amino acids in the Naja toxin (formed by 62 residues).

\subsection{Phylogenetic relationships}

Sequence alignments of mipartoxin-I with 67 related 3FTx proteins from nine elapid snake genera (Fig. 5) revealed identity values ranging from $70 \%$ to $38 \%$ for proteins found in other Micrurus venoms, with the exception of $M$. nigrocinctus, whose toxin presented only $23 \%$ sequence identity compared to mipartoxin-I. Identity values dropped to $38 \%$ or lower for proteins of elapid genera other than Micrurus, when compared to mipartoxin-I. The number and positions of cysteine residues of mipartoxin-I adhere to the conserved scheme of the short-chain 3FTxs, presenting 8 cysteines (Fig. 5).

A phylogeny of the elapid 3FTx sequences aligned in Fig. 5 was reconstructed by Bayesian inference, using the Akaike selection criterion and the WAG + G amino acid substitution model. The resulting phylogenetic tree presented a trichotomy, in which two groups are formed by short-chain neurotoxins, while a third includes both shortchain and long-chain neurotoxins, as well as short-chain cytotoxins (Fig. 6). The first group ("a" in Fig. 6) is well supported, with a posterior probability (PP) value of 0.95 , and subdivides into two lineages: one that includes only short-chain cytotoxins, from Naja, Hemachatus, and Aspidelaps species, and another that includes the long-chain neurotoxins from $O$. hannah, Naja melanoleuca and $D$. viridis ( $\mathrm{PP}=1.0$ ) together with the short-chain neurotoxins from Naja kaouthia, Naja sputatrix and B. candidus, which form a well-supported group $(\mathrm{PP}=1.0)$, and from 0 . hannah, $D$. angusticeps and $M$. nigrocinctus, whose phylogenetic relationships within this branch cannot be confidently established. The second group ("b" in Fig. 6) is formed by all the short-chain neurotoxins present in the different South American Micrurus species (M. mipartitus, Micrurus frontalis, Micrurus altirostris, Micrurus corallinus and Micrurus surinamensis), with the exception of $M$. nigrocinctus, the Central American coral snake. This second group is also wellsupported by significant PP values, and although it is clear that mipartoxin-I belongs to this group, its precise phylogenetic relationships with the other Micrurus toxins cannot be conclusively established. The highest identity scores of mipartoxin-I in the multiple alignment were obtained in comparison to toxins from $M$. frontalis (P86421, 70\%) and M. altirostris (AED89567, 68\%). Finally, the third group ("c" in Fig. 6) is formed by short-chain neurotoxins from P. textilis, O. scutellatus, O. microlepidotus, D. coronoides, O. hannah and $B$. fasciatus, with well-supported phylogenetic relationships ( $\mathrm{PP}=0.95-1.0$ ), except for the $B$. fasciatus toxin. The fact that the same snake species may contain in its venom different 3FTxs that belong to several phylogenetic and functional groups within this protein family is well reflected in the tree shown in Fig. 6.

\subsection{Toxic activities}

Mipartoxin-I showed a potent lethal effect in mice, when injected by the intraperitoneal route, with a median lethal dose $\left(\mathrm{LD}_{50}\right)$ of $0.06 \mu \mathrm{g} / \mathrm{g}$ body weight. Injected animals rapidly showed a general decrease in their activity followed by slow breathing, and died within few hours after injection. On the other hand, the toxin was not cytotoxic to the myogenic $\mathrm{C} 2 \mathrm{C} 12$ cells in vitro, at concentrations up to $180 \mu \mathrm{g} / \mathrm{ml}$.

Incubation of chick biventer cervicis preparations with mipartoxin-I $(0.1$ or $0.5 \mu \mathrm{g} / \mathrm{ml})$ resulted in complete and irreversible neuromuscular blockade after $46 \pm 2$ and $21 \pm 2$ min, respectively (Fig. 7A and B). This concentrationdependence was also evident in the times required for $50 \%$ blockade, which decreased by increasing toxin concentration ( $21 \pm 0.8$ and $8.4 \pm 0.7 \mathrm{~min}$, respectively). The toxin completely blocked the contractures to exogenous $\mathrm{ACh}$ without affecting the responses to $\mathrm{KCl}$, indicating an effect on post-synaptic nicotinic receptor function, without altering muscle fiber integrity. The twitch inhibition was not reverted by addition of neostigmine $(6 \mu \mathrm{M})$ after $80 \%$ blockade induced by mipartoxin-I $(0.5 \mu \mathrm{g} / \mathrm{ml}$, $n=3$ ), as well as after successive washings; also neostigmine did not prevent the complete blockade induced by the toxin, which continued being progressive at same time interval as in absence of neostigmine (data not shown).

In mouse phrenic nerve-diaphragm preparations, mipartoxin-I $(0.5 \mu \mathrm{g} / \mathrm{ml})$ caused complete neuromuscular 


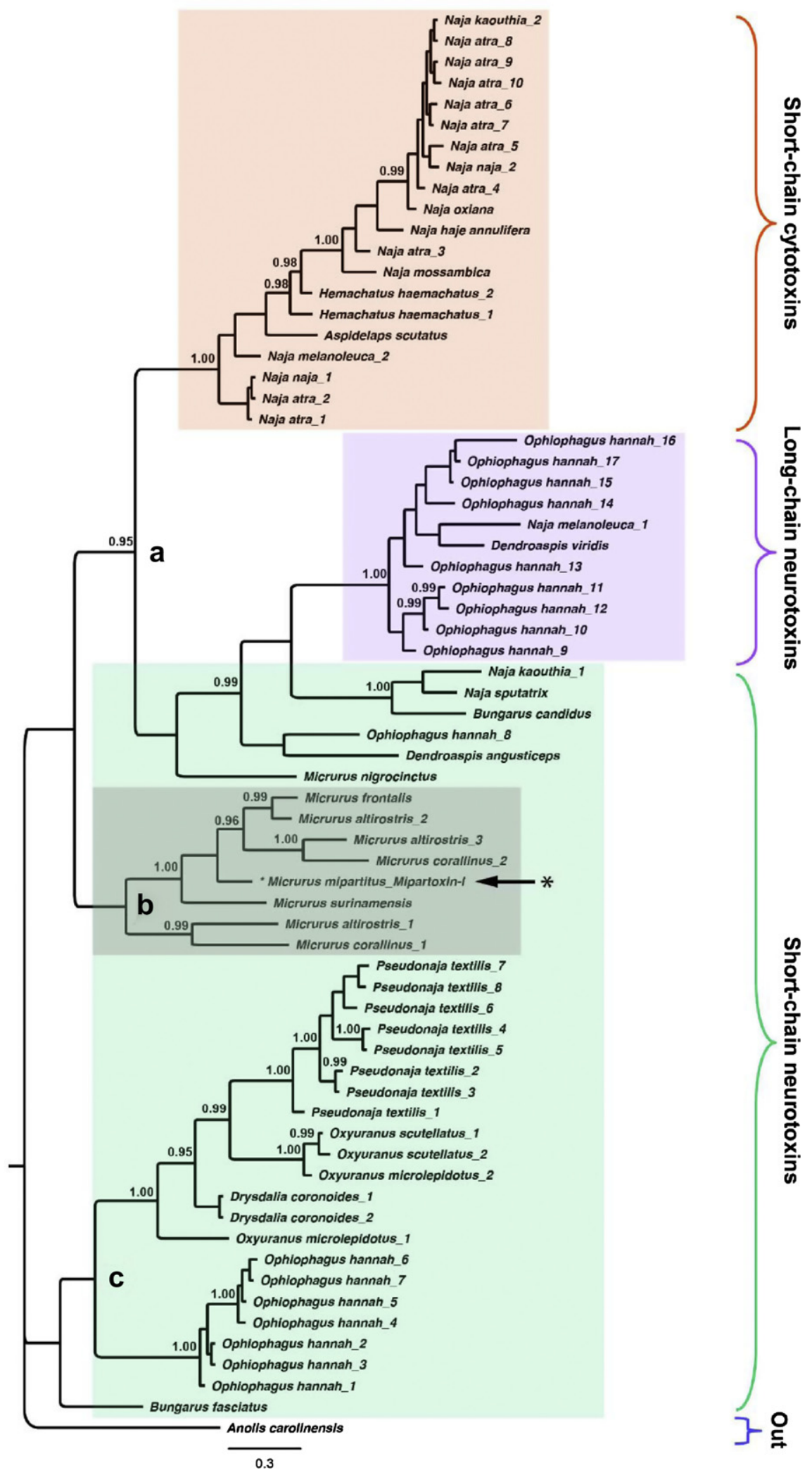

Fig. 6. Phylogenetic relationships of mipartoxin-I with three-finger toxins from elapid snake venoms. The sequences aligned in Fig. 5 were used to infer a phylogenetic tree, as described in Experimental. A hypothetical protein from the lizard Anolis carolinensis was utilized as outgroup (Out). The position of mipartoxin-I is pointed by a black arrow, within the group of related toxins from Micrurus species (gray shade). The three major functional groups within this family of proteins (short-chain cytotoxins, long-chain neurotoxins, and short-chain neurotoxins) are indicated by colored right braces and shading. Posterior probability values are shown in the tree nodes, when significant $(\geq 0.95)$. The three major branches (see Results) are indicated by letters (a, b, c). 


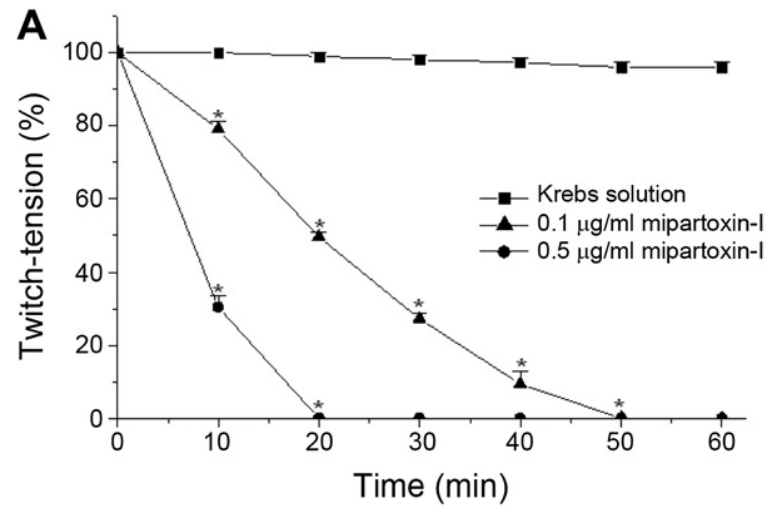

B

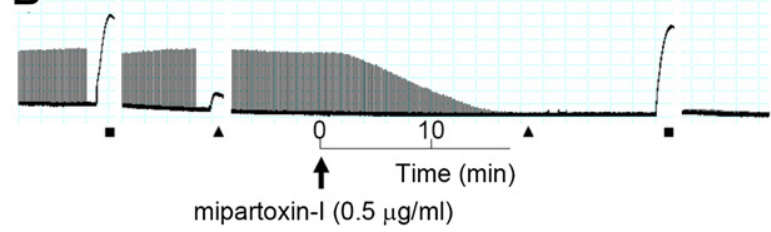

Fig. 7. Neuromuscular blockade produced by mipartoxin-I on isolated chick biventer cervicis preparations. (A) Concentration-dependent blockade curves caused by two different toxin doses, in comparison to control values (Krebs solution). (B) Representative record showing the neuromuscular blockade induced by mipartoxin-I $(0.5 \mu \mathrm{g} / \mathrm{ml})$ at $37{ }^{\circ} \mathrm{C}$, the inhibition of contractures to exogenous $\mathrm{ACh}(110 \mu \mathrm{M}, \boldsymbol{\Delta})$, and the lack of effect on the $\mathrm{KCl}$ $(40 \mathrm{mM}, \boldsymbol{\square})$ response. In $(\mathbf{A})$, points represent the mean $\pm \operatorname{SEM}(n=4)$. Asterisks indicate a statistically significant difference $(p<0.05)$ in comparison to the Krebs solution control.

blockade after $48 \pm 2 \mathrm{~min}$ (Fig. $8 \mathrm{~A}$ ), and at a concentration of $0.1 \mu \mathrm{g} / \mathrm{ml}$, induced $21 \%$ blockade after $120 \mathrm{~min}$. The complete twitch-tension blockade in this type of preparation was totally reversed $(97 \pm 2 \%)$ at $58 \pm 6 \mathrm{~min}$, after several washes (Fig. 8B). In mouse preparations pretreated with mipartoxin-I $(0.5 \mu \mathrm{g} / \mathrm{ml})$ and under tetanic stimulation $(70 \mathrm{~Hz}, 0.2 \mathrm{~ms}, \sim 4 \mathrm{~V}$ ) there was a progressive timedependent decrease in the amplitude of the response similar to that seen with a known post-synaptic acting toxin, $\alpha$-bungarotoxin (a non-depolarizing toxin, $1.0 \mu \mathrm{g} / \mathrm{ml}$, $n=4$ ) used as a positive-control (Fig. 8C).

Incubation with mipartoxin-I $(0.5 \mu \mathrm{g} / \mathrm{ml})$ did not alter the diaphragm resting membrane potential measurements (Fig. 9) after 60 min observation (control: $81 \pm 1.2-\mathrm{mV}$ vs. toxin: $79 \pm 1-\mathrm{mV} ; n=4$ ). Exposure of toxin-pretreated preparation to carbachol (Cch, $12.5 \mu \mathrm{g} / \mathrm{ml}$ ) did not interfere in the membrane potential values $(78 \pm 1 \mathrm{mV}$ after $15 \mathrm{~min}$, and $82 \pm 1-\mathrm{mV}$ after washing). Furthermore, mipartoxin-I $(0.5 \mu \mathrm{g} / \mathrm{ml})$ did not alter the frequency of MEPPs ( $37 \pm 7$ at $t_{0}$ to $27 \pm 4$ at $t_{45} \min ; n=3 ; p>0.05$ ), but significantly decreased the MEPPs amplitude values at 15 , 30 and $45 \mathrm{~min}$ incubation compared to basal values $(1.20 \pm 0.02 ; 0.98 \pm 0.01 ; 0.97 \pm 0.02$ and $0.89 \pm 0.01 \mathrm{mV}$ at $t_{0}, t_{15}, t_{30}$ and $t_{45} \mathrm{~min}$, respectively; $p<0.05$ ) as shown in the inset of Fig. 9.

\section{Discussion}

The major protein component of the venom of M. mipartitus from Colombia, here named mipartoxin-I, was isolated and characterized biochemically and functionally. Elucidation of its primary structure confirmed it as a new member of the 3FTx superfamily, presenting the characteristic cysteine signature and amino acid sequence lenght of the short-chain (or "type-I") $\alpha$-neurotoxins (Fry et al., 2003a,b). In similarity to all proteins of this family, mipartoxin-I is a basic protein, with a predicted pI of 8.5. Its observed molecular mass $\left(M_{r} 7030 \mathrm{Da}\right)$ matches the mass calculated from its amino acid sequence, indicating the lack of post-translational modifications. The anomalous migration of mipartoxin-I in SDS-PAGE, which overestimated its molecular weight at $\sim 10 \mathrm{kDa}$, might be related to its high isoelectric point, and hence, strong intrinsic positive charge.

Alignment of the sequence of mipartoxin-I with other proteins of the 3FTx family revealed considerable differences, with identity values not higher than $70 \%$, and mostly within the range of 25-55\%. The highest divergence from the few related toxins currently known in other Micrurus species was observed in comparison to the main $\alpha$-neurotoxin isolated from M. nigrocinctus (Rosso et al., 1996), surprisingly showing only $23 \%$ sequence identity. The Bayesian phylogenetic reconstruction of a large set of 3FTxs confirmed the divergence between this toxin from $M$. nigrocinctus, positioned within a clade of toxins from Old World elapid snakes, and mipartoxin-I, which is clearly related to toxins reported in South American Micrurus species, forming a monophyletic group. This finding is in agreement with a recently reported species phylogeny of Micrurus, in which M. mipartitus and Micrurus dissoleucus form a monophyletic group distant from M. nigrocinctus (Renjifo et al., 2012). Moreover, this divergence now clearly explains the long-known lack of immune cross-recognition of antivenoms prepared against $M$. nigrocinctus venom, when tested against M. mipartitus venom (Cohen et al., 1971; Bolaños et al., 1975, 1978; Rey-Suárez et al., 2011). The large sequence divergence here demonstrated between mipartoxin-I and $M$. nigrocinctus $\alpha$-neurotoxin should be expected to produce major antigenic differences between the epitopes of these two toxins. On the other hand, the higher identity values observed between mipartoxin-I and two related toxins from $M$. frontalis (70\%) and $M$. altirostris (68\%), suggest the possibility that antivenoms prepared against these two South American coral snake species might effectively cross-recognize and neutralize $M$. mipartitus venom, a hypothesis that deserves to be addressed experimentally, considering the scarcity of a specific antivenom against $M$. mipartitus.

The three-dimensional structure of toxins, and not only their primary structure, is crucial to their immunological and neutralizing properties (Ménez, 1985; Pergolizzi et al., 2005). Homology modeling of mipartoxin-I predicted a high structural similarity with CTXA5, a non-cytolytic 3FTx cardiotoxin isoform from the cobra $N$. atra (Wu et al., 2006), which provided the best template. It is interesting that the use of other 3FTx $\alpha$-neurotoxins as templates did not provide acceptable models, in contrast to CTXA5. In functional similarity with CTXA5, mipartoxin-I lacked cytolytic activity when tested on the murine myogenic cell line $\mathrm{C} 2 \mathrm{C} 12$, differing in this regard from many proteins of the 3FTx family classified as cardiotoxins/cytotoxins which have 


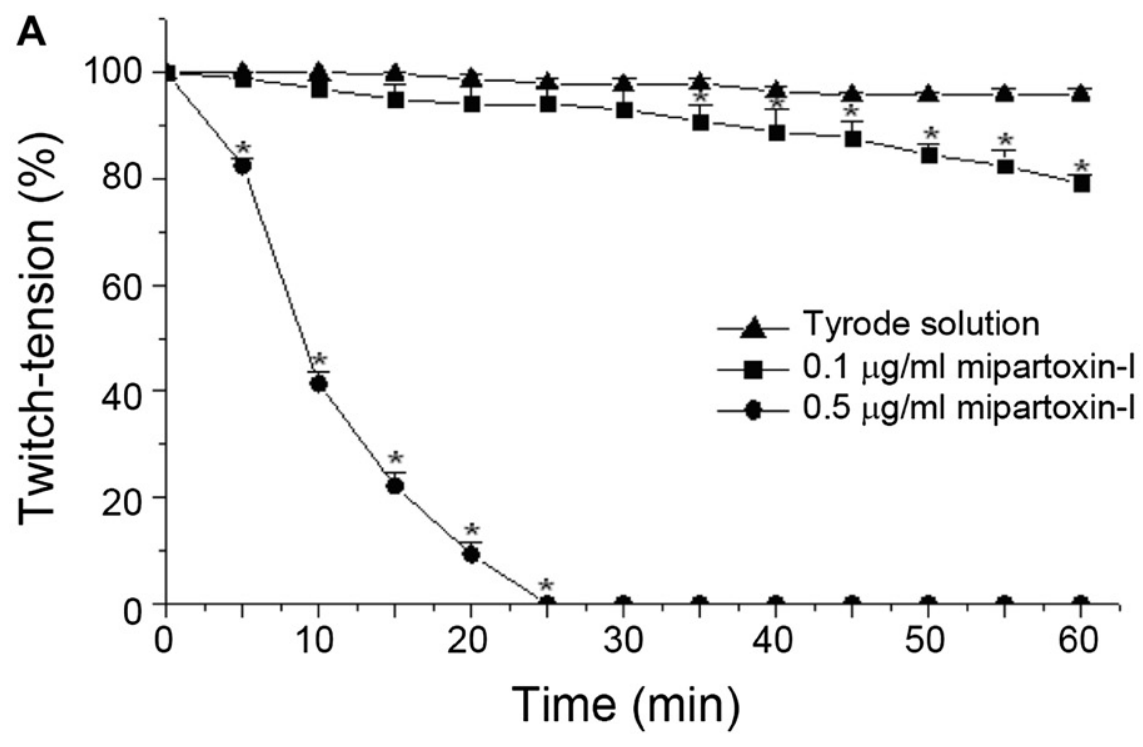

B

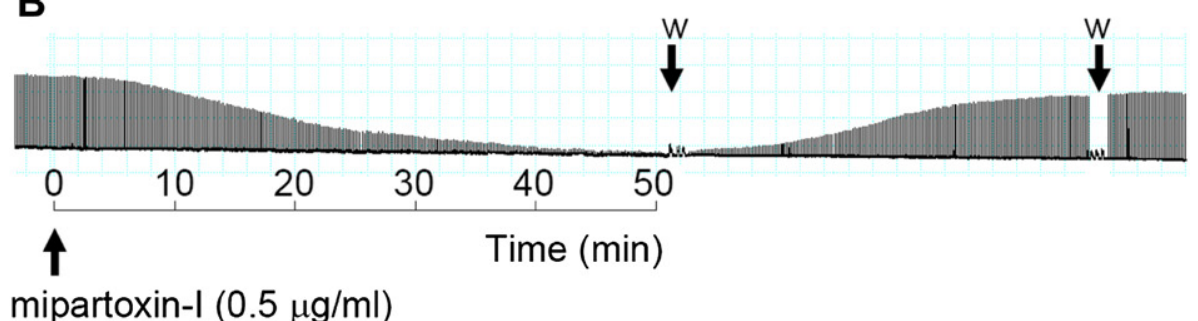

mipartoxin-I $(0.5 \mu \mathrm{g} / \mathrm{ml})$

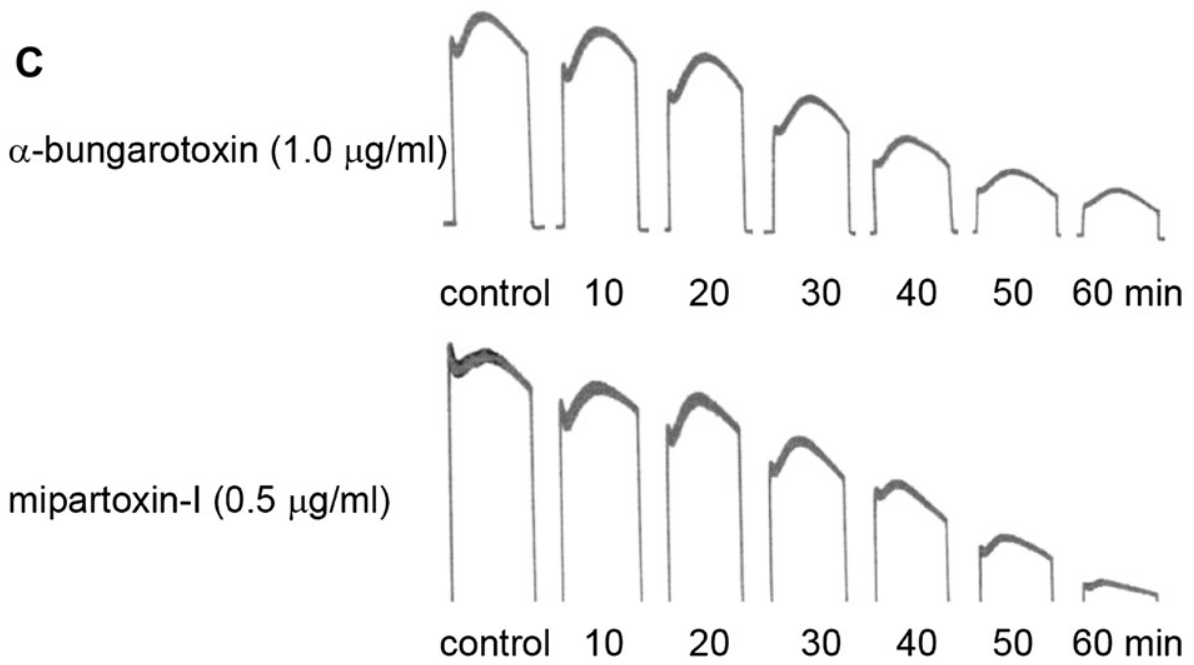

Fig. 8. Neuromuscular blockade produced by mipartoxin-I on isolated mouse phrenic nerve-diaphragm preparations. (A) Concentration-dependent blockade curves caused by two different toxin doses, in comparison to control values (Tyrode solution). (B) Representative record showing the complete neuromuscular blockade and the reversible blocking effect by washing $(\mathrm{W})$, at $37^{\circ} \mathrm{C}$. (C) Representative record for $0.5 \mu \mathrm{g}$ of toxin/ml showing the effect on the tetanic stimulation (0-60 $\mathrm{min})$ compared with $1.0 \mu \mathrm{g}$ of $\alpha$-bungarotoxin/ml, as a positive-control. Note that the response to the tetanic stimulation after incubation with mipartoxin-I was similar to that recorded after exposure to $\alpha$-bungarotoxin. In $(\mathbf{A})$, points represent the mean $\pm \operatorname{SEM}(n=4)$. Asterisks indicate a statistically significant difference $(p<0.05)$ in comparison to the Tyrode solution control.

a general cytolytic effect in vitro (Harvey, 1990; Méndez et al., 2011). CTXA5 has been reported to bind to $\alpha \mathrm{v} \beta 3$ integrins without exerting cytolysis (Wu et al., 2006). Examination of the structural model of mipartoxin-I shows a highly conserved core in comparison to CTXA5, but slight spatial differences at the tips of the loops 2 and 3, and a major change in loop 3. The loops interconnecting these all- $\beta$-sheet proteins have been associated with their target 


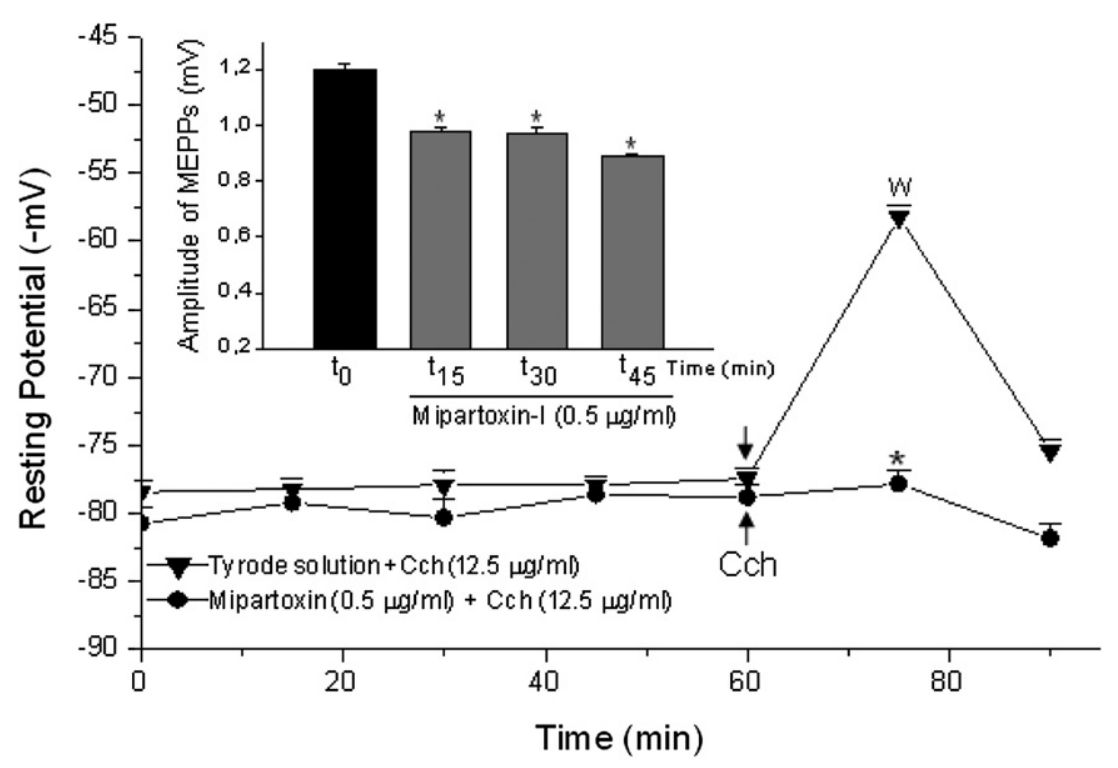

Fig. 9. Lack of depolarization of the mouse hemidiaphragm muscle membrane resting potential by mipartoxin-I after 60 min, and significant change in the response to exogenous carbachol (Cch, $12.5 \mu \mathrm{g} / \mathrm{ml}$ ) after $60 \mathrm{~min}$ compared to control preparations $\left(T_{0}\right)$. Points represent mean \pm SEM $(n=4)$. Inset: effect of mipartoxin-I $(0.5 \mu \mathrm{g} / \mathrm{ml})$ on the amplitude of MEPPs at room temperature before and at different times after exposure to toxin. Asterisks indicate a statistically significant difference $(p<0.05)$ in comparison to control preparations.

specificity (Dubovskii et al., 2001; Fry et al., 2003a,b; Kini and Doley, 2010; Kini, 2011), and hence with their functional properties in vivo.

Considering the biochemical, structural, and phylogenetic characteristics of mipartoxin-I, together with its high lethal action in mice $\left(\mathrm{LD}_{50} 0.06 \mu \mathrm{g} / \mathrm{g}\right.$ ), its possible neurotoxic activity was investigated. Mipartoxin-I caused a clear neuromuscular blockade on both avian and mammalian preparations. The biventer cervicis preparation was more sensitive than the phrenic nerve-diaphragm preparation, probably related to differences in the innervation of these two preparations, with avian muscle having both focally- and multiply-innervated fibers that can respond to electrical stimulation or exogenous nicotinic agonists (Hodgson and Wickramaratna, 2002). The inability of neostigmine and several washings to revert the toxininduced inhibition in BC preparations agrees with the findings recently reported in preparations incubated with crude venom of $M$. mipartitus (Renjifo et al., 2012). However, possible species differences in the affinity of this toxin for its receptors cannot be ruled out. Mipartoxin-I inhibited contractures to exogenous ACh, indicating a predominantly post-synaptic action through the blockade of cholinergic nicotinic receptor, as also suggested for other studies using Micrurus venoms (Goularte et al., 1995; Serafim et al., 2002; Abreu et al., 2008; Camargo et al., 2011; Renjifo et al., 2012). The post-synaptic action of mipartoxin-I was also indicated by the absence of fade in the response to tetanic indirect stimulation at $70 \mathrm{~Hz}$. This tetanic pattern was similar to that produced by $\alpha$-bungarotoxin, a non-depolarizing toxin (Gallacci and Oliveira, 1994; Serra and Oliveira, 2006; Camargo et al., 2011). These results were corroborated using carbachol to produce progressive depolarization of the resting membrane potential, whereas the toxin had no effect on this parameter, indicating an activity on the post-synaptic nicotinic receptors. Moreover, the inability of mipartoxin-I to alter the MEPPs frequency, in contrast with its efficiency in decreasing MEPPs amplitude, suggests that, like other typical $\alpha$-neurotoxins, the toxin binds nicotinic receptors without interfering with the presynaptic mechanism of neurotransmitter release. Taken together, these results indicate that mipartoxin-I causes neuromuscular blockade by a post-synaptic action in neuromuscular preparations, i.e. $\alpha$-neurotoxicity, without directly damaging muscle fibers. The small amounts of toxin available precluded further characterization of its receptor subtype specificity. A recent study evaluated the neuromuscular activity of the crude venom of $M$. mipartitus on the chick biventer cervicis preparation, and demonstrated a post-synaptic action (Renjifo et al., 2012), in full agreement with the present findings using its purified major neurotoxin, mipartoxin-I, and also supporting the conclusion that this protein plays a central role in the neurotoxicity of $M$. mipartitus venom.

The extraordinary biodiversity within the genus Micrurus, with more than 70 species described (Castoe et al., 2007), seems to be also reflected in the wide divergence emerging from the study of their venom toxins. Only a handful of 3FTxs have been fully sequenced and functionally characterized from Micrurus venoms (Rosso et al., 1996; de Oliveira et al., 2000; Dokmetjian et al., 2009; Moreira et al., 2010). Mipartoxin-I, isolated from M. mipartitus venom, is a novel member of the 3FTx superfamily with a potent post-synaptic $\alpha$-neurotoxic effect on both avian and mammalian neuromuscular preparations, and lethal action in mice. Since mipartoxin-I is the most abundant (28\%) protein in the venom of this coral snake species, it would be expected to play a major role in its toxicity. Therefore, mipartoxin-I should be a relevant target for the 
development of a therapeutic antivenom. Together with its functional characterization, the structural information reported in the present work might be useful in the preparation of a synthetic or recombinant immunogen to overcome the scarcity of venom for immunization.

\section{Conflicts of interest}

None to declare.

\section{Acknowledgments}

We thank Dr Jean-Pierre Rosso (Laboratoire de Biochimie, Université de la Mediterranee, Marseille, France) and Dr Juan J. Calvete (Laboratorio de Proteinómica Estructural, Instituto de Biomedicina de Valencia, Spain) for their expert suggestions, and Gildo Bernardo Leite and Fabián Villalta for technical assistance. Support was provided by a Young Researcher Fellowship to P. Rey by COLCIENCIAS (1115-45921441) and Universidad de Antioquia, Colombia, and by Vicerrectoría de Investigación, Universidad de Costa Rica (741-A9-513). This study was performed as part of the M.Sc. thesis of P. Rey at the University of Antioquia.

\section{References}

Abascal, F., Zardoya, R., Posada, D., 2005. ProtTest: selection of best-fit models of protein evolution. Bioinformatics 21, 2104-2105.

Abreu, V.A., Leite, G.B., Oliveira, C.B., Hyslop, S., Furtado, M.F., RodriguesSimioni, L., 2008. Neurotoxicity of Micrurus altirostris (Uruguayan coral snake) venom and its neutralization by commercial coral snake antivenom and specific antiserum raised in rabbits. Clin. Toxicol. 46, 519-527.

Altschul, S.F., Gish, W., Miller, W., Myers, E.W., Lipman, D.J., 1990. Basic local alignment search tool. J. Mol. Biol. 215, 403-410.

Bolaños, R., Cerdas, L., Abalos, J.W., 1978. Venenos de las serpientes coral (Micrurus spp.): informe sobre un antiveneno polivalente para las Américas. Bol. Ofic. Sanit. PanAm. 84, 128-133.

Bolaños, R., Cerdas, L., Taylor, R., 1975. The production and characteristics of a coral snake (Micrurus mipartitus hertwigi) antivenin. Toxicon 13, 139-142.

Bülbring, E., 1946. Observations on the isolated phrenic-nerve diaphragm preparation of the rat. Br. J. Pharmacol. 1, 38-61.

Calvete, J.J., Sanz, L., Angulo, Y., Lomonte, B., Gutiérrez, J.M., 2009. Venom, venomics, antivenomics. FEBS Lett. 583, 1736-1743.

Camargo, T.M., Roodt, A.R., Cruz-Höfling, M.A., Rodrigues-Simioni, L., 2011. The neuromuscular activity of Micrurus pyrrhocryptus venom and its neutralization by commercial and specific coral snake antivenoms. J. Venom Res. 2, 24-31.

Castoe, T.A., Smith, E.N., Brown, R.M., Parkinson, C.L., 2007. Higher-level phylogeny of Asian and American coralsnakes, their placement within the Elapidae (Squamata), and the systematic affinities of the enigmatic Asian coralsnake Hemibungarus calligaster (Wiegmann, 1834). Zool. J. Linnean Soc. 151, 809-831.

Ciscotto, P.H.C., Rates, B., Silva, D.A.F., Richardson, M., Silva, L.P., Andrade, H., Donato, M.F., Cotta, G.A., Maria, W.S., Rodrigues, R.J., Sanchez, E., De Lima, M.E., Pimenta, A.M.C., 2011. Venomic analysis and evaluation of antivenom cross-reactivity of South American Micrurus species. J. Proteomics 74, 1810-1825.

Cohen, P., Berkeley, W.H., Seligmann, E.B., 1971. Coral snake venoms. In vitro relation of neutralizing and precipitating antibodies. Am. J. Trop. Med. Hyg. 20, 646-649.

Corrêa-Netto, C., Junqueira-de-azevedo, I., Silva, D., Ho, P.L., Leitão-deAraújo, M., Alves, M.L., Sanz, L., Foguel, D., Zingali, R.B., Calvete, J.J., 2011. Snake venomics and venom gland transcriptomic analysis of Brazilian coral snakes, Micrurus altirostris and M. corallinus. J. Proteomics 74, 1795-1809.

de Oliveira, J.S., da Silva, A.R.B., Soares, M.B., Stephano, M.A., Dias, W.O., Raw, I., Ho, P.L., 2000. Cloning and characterization of an $\alpha$-neurotoxin-type protein specific for the coral snake Micrurus corallinus. Biochem. Biophys. Res. Comm. 267, 887-891.
Dokmetjian, J.C., del Canto, S., Vinzón, S., Bonino, M.B.J., 2009. Biochemical characterization of Micrurus pyrrhocryptus venom. Toxicon 53, 375-382.

Dubovskii, P.V., Dementieva, D.V., Bocharov, E.V., Utkin, Y.N., Arseniev, A.S., 2001. Membrane binding motif of the P-type cardiotoxin. J. Mol. Biol. 305, 137-149.

Fernández, J., Alape-Girón, A., Angulo, Y., Sanz, L., Gutiérrez, J.M., Calvete, J.J., Lomonte, B., 2011. Venomic and antivenomic analyses of the Central American coral snake, Micrurus nigrocinctus (Elapidae). J. Proteome Res. 10, 1816-1827.

Fry, B.G., Vidal, N., Normamn, J.A., Vonk, F.J., Scheib, H., Ramjan, S.F., Kuruppu, S., Fung, K., Hedges, S.B., Richardson, M.K., Hodgson, W.C., Ignjatovic, V., Summerhayes, R., Kochva, E., 2006. Early evolution of the venom system in lizards and snakes. Nature 439, 584-588.

Fry, B.G., Wuster, W., Kini, R.M., Brusic, V., Khan, A., Venkataraman, D., Rooney, A.P., 2003a. Molecular evolution and phylogeny of elapid snake venom three-finger toxins. J. Mol. Evol. 57, 110-129.

Fry, B.G., Wüster, W., Ramjan, S.F.R., Jackson, T., Martelli, P., Kini, R.M., 2003b. Analysis of Colubroidea snake venoms by liquid chromatography with mass spectrometry: evolutionary and toxinological implications. Rap. Comm. Mass Spectrom. 17, 2047-2062.

Gallacci, M., Oliveira, A.C., 1994. Pre- and postsynaptic mechanisms involved in fade induced by pancuronium in the isolated rat muscle. Pharmacology 49, 265-270.

Ginsborg, B.L., Warriner, J., 1960. The isolated chick biventer cervicis nerve muscle preparation. Br. J. Pharmacol. Chemother. 15, 410-411.

Goularte, F.C., Cruz-Höfling, M.A., Cogo, J.C., Gutiérrez, J.M., RodriguesSimioni, L., 1995. The ability of specific antivenom and low temperature to inhibit the myotoxicity and neuromuscular block induced by Micrurus nigrocinctus venom. Toxicon 33, 679-689.

Guex, N., Peitsch, M.C., 1997. SWISS-MODEL and the Swiss-PdbViewer: an environment for comparative protein modeling. Electrophoresis 18, 2714-2723.

Hall, T.A., 1999. BioEdit: a user-friendly biological sequence alignment editor and analysis program for Windows 95/98/NT. Nucl. Acids Symp. Ser. 41, 95-98.

Harvey, A.L., 1990. Cytolytic toxins. In: Shier, W.R., Mebs, D. (Eds.), Handbook of Toxinology. Marcel Dekker, New York, pp. 48-53.

Harvey, A.L., Barfaraz, A., Thomson, E., Faiz, A., Preston, S., Harris, J.B., 1994. Screening of snake venoms for neurotoxic and myotoxic effects using simple in vitro preparations from rodents and chicks. Toxicon 32, 257-265.

Hodgson, W.C., Wickramaratna, J.C., 2002. In vitro neuromuscular activity of snake venoms. Clin. Exp. Pharmacol. Physiol. 29, 807-814.

Kiefer, F., Arnold, K., Künzli, M., Bordoli, L., Schwede, T., 2009. The SWISSMODEL repository and associated resources. Nucl. Acids Res. 37, D387-D392.

Kini, R.M., 2011. Evolution of three-finger toxins - a versatile mini protein scaffold. Acta Chim. Slov 58, 693-701.

Kini, R.M., Doley, R., 2010. Structure, function and evolution of three-finger toxins-mini proteins with multiple targets. Toxicon 56, 855-867.

Laskowski, R.A., MacArthur, M.W., Moss, D., Thornton, J.M., 1993. PROCHECK: a program to check the stereochemical quality of protein structures. J. Appl. Cryst 26, 283-291.

Lomonte, B., Angulo, Y., Rufini, S., Cho, W., Giglio, J.R., Ohno, M., Daniele, J.J., Geoghegan, P., Gutiérrez, J.M., 1999. Comparative study of the cytolytic activity of myotoxic phospholipases $A_{2}$ on mouse endothelial (tEnd) and skeletal muscle (C2C12) cells in vitro. Toxicon 37, 145-158.

Méndez, I., Gutiérrez, J.M., Angulo, Y., Calvete, J.J., Lomonte, B., 2011. Comparative study of the cytolytic activity of snake venoms from African spitting cobras (Naja spp., Elapidae) and its neutralization by a polyspecific antivenom. Toxicon $58,558-564$.

Ménez, A., 1985. Molecular immunology of snake toxins. Pharmac. Ther. $30,91-113$

Moreira, K.G., Prates, M.V., Andrade, F.A.C., Silva, L.P., Beirao, P.S.L., Kushmerick, C., Naves, L.A., Bloch Jr., C., 2010. Frontoxins, three-finger toxins from Micrurus frontalis venom, decrease miniature endplate potential amplitude at frog neuromuscular junction. Toxicon 56, 55-63.

Nakashima, K.-I., Ogawa, T., Oda, N., Hattori, M., Sakaki, Y., Kihara, H., Ohno, M., 1993. Accelerated evolution of Trimeresurus flavoviridis venom gland phospholipase $A_{2}$ isozymes. Proc. Natl. Acad. Sci. USA 90, 5964-5968.

Olamendi-Portugal, T., Batista, C., Restano-Cassulini, R., Pando, V., Villa-Hernandez, O., Zavaleta-Martínez-Vargas, A., Salas-Arruz, M.C., Rodríguez de la Vega, R.C., Becerril, B., Possani, L., 2008. Proteomic analysis of the venom from the fish eating coral snake Micrurus surinamensis: novel toxins, their function and phylogeny. Proteomics 8, 1919-1932.

Oshima-Franco, Y., Leite, G.B., Belo, C.A., Hyslop, S., Prado-Franceschi, J., Cintra, A.C., Giglio, J.R., Cruz-Höfling, M.A., Rodrigues-Simioni, L., 
2004. The presynaptic activity of bothropstoxin-I, a myotoxin from Bothrops jararacussu snake venom. Basic Clin. Pharmacol. Toxicol. 95, 175-182.

Otero, R., 1994. Manual de diagnóstico y tratamiento del accidente ofídico. Editorial Universidad de Antioquia, Medellín (Colombia), pp. 1-15.

Pergolizzi, R.G., Dragos, R., Ropper, A.E., Ménez, A., Crystal, R.G., 2005. Protective immunity against alpha-cobratoxin following a single administration of a genetic vaccine encoding a non-toxic cobratoxin variant. Hum. Gene Ther. 16, 292-298.

Renjifo, C., Smith, E.N., Hodgson, W.C., Renjifo, J.M., Sanchez, A., Acosta, R., Maldonado, J.H., Riveros, A., 2012. Neuromuscular activity of the venoms of the Colombian coral snakes Micrurus dissoleucus and Micrurus mipartitus: an evolutionary perspective. Toxicon 59, 132142.

Rey-Suárez, P., Núñez, V., Gutiérrez, J.M., Lomonte, B., 2011. Proteomic and biological characterization of the venom of the redtail coral snake, Micrurus mipartitus (Elapidae), from Colombia and Costa Rica. J. Proteomics 75, 655-667.
Ronquist, F., Huelsenbeck, J.P., 2003. MrBayes 3: Bayesian phylogenetic inference under mixed models. Bioinformatics 19, 1572-1574.

Rosso, J.P., Vargas-Rosso, O., Gutierrez, J.M., Rochat, H., Bougis, P.E., 1996. Characterization of alpha-neurotoxin and phospholipase $A_{2}$ activities from Micrurus venoms. Determination of the amino acid sequence and receptor-binding ability of the major alpha-neurotoxin from Micrurus nigrocinctus nigrocinctus. Eur. J. Biochem. 238, 231-239.

Serafim, F.G., Reali, M., Cruz-Höfling, M.A., Fontana, M.D., 2002. Action of Micrurus dumerilli carinicauda coral snake venom on the mammalian neuromuscular junction. Toxicon 40, 167-174.

Serra, C.S.M., Oliveira, A.C., 2006. Cisatracurium: myographical and electrophysiological studies in the isolated rat muscle. Fund. Clin. Pharmacol. 20, 291-298.

Trevors, J.T., 1986. A BASIC program for estimating $\mathrm{LD}_{50}$ values using the IBM-PC. Bull. Environ. Contam. Toxicol. 37, 18-26.

Wu, P.L., Lee, S.C., Chuang, C.C., Mori, S., Akakura, N., Wu, W.G., Takada, Y., 2006. Non-cytotoxic cobra cardiotoxin A5 binds to $\alpha \mathrm{v} \beta 3$ integrin and inhibits bone resorption. J. Biol. Chem. 281, 7937-7945. 